J. Dairy Sci. 92:375-381

doi:10.3168/jds.2008-1143

(c) American Dairy Science Association, 2009.

\title{
Antibody response against three widespread bovine viruses is not impaired in Holstein cattle carrying bovine leukocyte antigen DRB3.2 alleles associated with bovine leukemia virus resistance
}

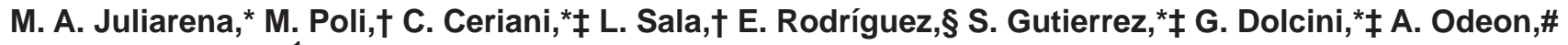 \\ and E. N. Esteban*1 \\ *Laboratorio de Virología del Departamento Sanidad Animal y Medicine Preventiva (SAMP), Facultad de Ciencias Veterinarias-Universidad \\ Nacional del Centro de la Provincia de Buenos Aires (FCV-UNCPBA), Pinto 399, (7000) Tandil, Argentina \\ †Instituto de Genética del Centro de investigaciones en Ciencias Veterinarias, Instituto Nacional de Tecnología Agropecuaria, Castelar, Argentina \\ $\ddagger$ Carrera de investigador científico-Consejo Nacional de Investigaciones Cientificas y Técnicas, Argentina \\ §Departamento SAMP, FCV-UNCPBA, (7000) Tandil, Argentina \\ \#Laboratorio de Virología, Instituto Nacional de Tecnología Agropecuaria, Balcarce, Argentina
}

\begin{abstract}
Due to the wide dissemination of bovine leukemia virus (BLV) infection among dairy cattle, control and eradication programs based on serological detection of infected cattle and subsequent culling face a major economic task. In Argentina, genetic selection of cattle carrying alleles of the bovine leukocyte antigen $(B o L A)$ DRB3.2 gene associated with BLV-infection resistance, like *0902, emerges as the best additional tool toward controlling virus spread. A potential risk in expanding or segregating BoLA selected populations of cattle is that it might increase susceptibility to other common viruses. Special concern raises the strong association found between low proviral load and low antibody titer against major BLV structural proteins. This phenomenon might depend on host genetic factors influencing other viruses requiring, unlike BLV, strong and longlasting humoral immune response to prevent infection. In this study, we demonstrate that there is no association among neutralizing antibody titers against foot and mouth disease virus, bovine viral diarrhea virus, or bovine herpesvirus type 1 and polymorphism of the $B o L A$ $D R B 3.2$ gene. Conversely, there is strong association between BoLA DRB3.2*0902 and low antibody titers against 2 BLV structural proteins - env gp51 and gag p24 - to date, the best BLV resistance marker. There is also significant association between low antibody titers against gp51 and p24 and BoLA DRB3.2*1701 and low antibody titers against p24 and BoLA DRB3.2*1101 or 02. Our data suggest that increasing $B o L A$-selected BLV-resistant cattle or segregating BoLA-associated alleles to BLV susceptibility would not affect the resistance or the predisposition to bovine viral diarrhea
\end{abstract}

Received March 3, 2008

Accepted September 15, 2008.

${ }^{1}$ Corresponding author: esteban@vet.unicen.edu.ar virus, bovine herpesvirus type 1 , or foot and mouth disease virus infection.

Key words: bovine leukocyte antigen $D R B 3.2^{*}$, bovine virus, humoral response

\section{INTRODUCTION}

Bovine leukemia virus (BLV) is a Deltaretrovirus (Fauquet et al., 2005) of the Retroviridae family. Bovine leukemia virus is the etiological agent of the deadly bovine lymphosarcoma and the nonmalignant condition known as persistent lymphocytosis (PL). Less than $10 \%$ BLV-infected cattle develop lymphosarcoma, and about $30 \%$ develop PL. Bovine leukemia virus has been almost eradicated from western European countries, but it is still endemic in most other countries worldwide. Direct economic losses depend on the lymphosarcoma mortality, and the frequency of this disease directly depends on BLV prevalence at herd level.

Finding a safe vaccine preventing BLV infection has been elusive. Probably, the most promising approach in this field has been the design of BLV G3 and G4 genes deleted strains (Willems et al., 1994). Although these BLV-deleted strains still have not been exhaustively tested in cattle, vaccinated sheep showed convincing long-term protection against wild-type BLV (Reichert et al., 2000). The observation of residual oncogenic potential of these deleted strains in vaccinated sheep has been recently communicated (Florins et al., 2007b).

Alternative approaches have been made targeting BLV control through genetic selection. We have recently found a strong association between certain alleles of the bovine leukocyte antigen ( $\boldsymbol{B o L} \boldsymbol{A})$ DRB3.2* gene and a BLV-infection profile named low proviral load $(\mathbf{L P L}$; Juliarena et al., 2008). After being infected, cattle carrying the alleles BoLA DRB3.2*0902 or *1701 develop an exiguous infection, a characteristic low-titer anti- 
body response against the BLV env gp51 and, mainly, no antibody response against gag p24. Long-term consistency of this viral and humoral immune response status defines the LPL BLV-infection profile.

On the other hand, the development of high antibody titer against the major structural proteins gp51 and p24 after BLV infection has been associated with the development of high proviral load. Consistency over time of this condition, which includes cattle that develop PL and about 40\% nonlymphocytotic cattle, has been defined as high proviral load (HPL) BLVinfection profile. Animals having this profile are considered efficient transmitters of the virus. Conversely, LPL animals are suggested as not being risky transmitters under standard husbandry conditions (Juliarena et al., 2007). Those findings indicate that genetic selection of cattle carrying alleles ${ }^{*} 0902,{ }^{*} 1701$, or both would be a useful tool toward controlling BLV.

As has been suggested, it is likely that after BLV infection antibody level is a consequence of the proviral load setup (Gillet et al., 2007). However, low antibody titer or lack of antibody response against gag p24 might also be influenced directly by bovine genetic factors like BoLA DRB3.2* alleles associated to BLV resistance. In this case, a key question is whether this is a BLV-specific phenomenon or whether it involves other viruses requiring, unlike BLV, strong humoral immune response elicited by the host attaining their control. Thus, expansion of BoLA-defined populations to control BLV creates the need to determine if selected cattle would be more susceptible to other common viruses.

Bovine viral diarrhea virus (BVDV), a Pestivirus of the Flaviviridae family (Fauquet et al., 2005) and the bovine herpesvirus type 1 (BHV-1), a Varicellovirus of the Herpetoviridae family (Fauquet et al., 2005), are endemic in most countries. The foot and mouth disease virus (FMDV), an Aphtovirus of the Picornaviridae family (Fauquet et al., 2005), was eradicated from several countries, but it is endemic in most other countries all over the world. Each of the aforementioned bovine viruses causes diseases and syndromes that negatively affect the economic performance of the dairy and beef cattle industries.

Having high neutralizing antibody titers against FMDV (Capozzo et al., 1997), BVDV (Bolin and Ridpath, 1995), or BHV-1 (Babiuk et al., 1996) is a desired condition, which is considered as a protection indicator. Besides, high-responder animals are not considered to be at risk of transmitting the respective viruses. Consequently, protection against these 3 viruses is achieved when high titers of neutralizing antibodies are raised. Thus, the determination of the titer of neutralizing antibodies is considered an adequate indicator of resistance against these 3 viruses.
Licensed vaccines against BHV-1, FMDV, and BVDV are available, and vaccination against these viruses with inactivated vaccines is a common practice in Argentinean herds. Whereas vaccination against FMDV has succeeded toward controlling and even eradicating the virus (Orsel et al., 2007), advantages in vaccinating cattle against $\mathrm{BHV}-1$ and $\mathrm{BVDV}$ have been largely controversial (Bolin, 1995; Babiuk et al., 1996; van Oirschot, 1999; Kelling, 2004). The identification of factors influencing the humoral immune response against these viruses would probably also contribute to avoiding the undesired selection of low responders found after vaccinations.

In a previous report, the polymorphism of the $B o L A$ DRB3.2* gene was not associated with the antibody response to FMDV peptides in 46 cows experimentally inoculated (Garcia-Briones et al., 2000). Up to this date, no information is found in the literature about the influence of host genetic factors on neutralizing antibody titer against BHV-1 or BVDV in commercial dairy herds.

In this study, we present results obtained by associating antibody titer against BVDV, BHV-1, FMDV, and 2 structural proteins of BLV with BoLA DRB3.2* gene polymorphism. This information might be useful to reduce the undesired selection of cattle susceptible to several viral diseases.

\section{MATERIALS AND METHODS}

\section{Animals}

A total of 241 BLV-infected cows from 7 dairy herds located in different regions of Argentina were selected for this study (Table 1). Cattle vaccination against FMDV is mandatory every $6 \mathrm{mo}$ in Argentina. Vaccination against BVDV and BHV-1 is a recommended procedure to keep high immunity against these viruses. Cattle are vaccinated in early spring and autumn. Cattle belonged to the Argentinean Holstein dairy breed and were more than $3 \mathrm{yr}$ old. All herds had more than 100 milking cows.

\section{Blood Samples}

Blood samples from each animal were obtained by jugular or coccygeal venipuncture in heparinized (5 U/ $\mathrm{mL}$ ) syringes. Plasma was harvested after blood sample centrifugation for $20 \mathrm{~min}$ at $2,000 \times \mathrm{g}$. Sodium azide was added (final concentration $0.2 \%$ ), and the plasma aliquots were stored at $-20^{\circ} \mathrm{C}$ until use. Peripheral blood leucocytes were obtained by mixing the buffy coat with $11 \mathrm{~mL}$ of cold $150 \mathrm{mM} \mathrm{NH} \mathrm{N}_{4} \mathrm{Cl}, 8 \mathrm{mM} \mathrm{Na}_{2} \mathrm{CO}_{3}$, $6 \mathrm{mM}$ EDTA, $\mathrm{pH} 7$ for $1 \mathrm{~min}$ to completely lyse the red 
blood cells. The cell pellet obtained after centrifugation at $1,000 \times g$ for $7 \mathrm{~min}$ at $4^{\circ} \mathrm{C}$ was resuspended in 1 $\mathrm{mL}$ of PBS solution, transferred to a $1.5-\mathrm{mL}$ tube, and centrifuged at $10,000 \times g$ for $2 \mathrm{~min}$. The supernatant was discarded, and the peripheral blood leucocytes were stored at $-20^{\circ} \mathrm{C}$. The DNA was organically extracted from peripheral blood leucocytes by phenol-chloroform extraction, ethanol precipitated, quantified by spectrophotometry, and stored at $-20^{\circ} \mathrm{C}$.

\section{Determination of Antibody Titer Against BLVgp51 and BLVp24}

The titer of antibodies against BLVgp51 and BLVp24 were determined by testing 2-fold dilutions (from 1:50 to 1:6,400) of plasma samples in ELISA 108 and ELISA Rp24, respectively. The characteristics and performance of both immunoassays have been described (Gutierrez et al., 2001; Juliarena et al., 2007)

\section{Determination of the Neutralizing Antibody Titer against BVDV}

Plasma samples were tested for the presence of virus neutralizing antibodies against BVDV using a standard microtitration procedure on Madin-Darby bovine kidney (MDBK) cells (Maisonnave and Rossi, 1982). Samples were heat inactivated at $56^{\circ} \mathrm{C}$ for $30 \mathrm{~min}$. Infected cells were detected by visualization of viral cytopathic effect under inverted microscope. Neutralizing titers were determined according to the described method (Reed and Muench, 1938).

\section{Determination of Neutralizing Antibody Titer Against BHV-1}

The presence of neutralizing antibodies against BHV-1 was determined by a microtitration procedure on MDBK cell cultures (Van der Maaten et al., 1985). Neutralizing titers were expressed as the highest dilution of plasma that completely neutralized the viral cytopathic effect after a 72-h incubation period.

\section{Determination of Neutralizing Antibody Titer Against FMDV}

Antibodies against FMDV were determined on plasma samples by a liquid-phase ELISA as indicated (Robiolo et al., 2006).

\section{Genotyping of BoLA DRB3.2}

The BoLA DRB3.2* genotyping of animals was performed by 2 methods, PCR-RFLP and PCR-sequence-
Table 1. Number of selected cattle per herd

\begin{tabular}{lc}
\hline $\begin{array}{l}\text { Herd } \\
\text { number }\end{array}$ & $\begin{array}{c}\text { Animals } \\
\text { studied, } \mathrm{n}\end{array}$ \\
\hline 1 & 38 \\
2 & 26 \\
3 & 24 \\
4 & 26 \\
5 & 38 \\
6 & 65 \\
7 & 24 \\
Total & 241 \\
\hline
\end{tabular}

specific oligonucleotide as already described (Juliarena et al., 2008).

The PCR-RFLP method was used in this study because it had been previously used in most of the association studies of BoLA-DRB3.2* gene with BLV or FMDV. The PCR-sequence-specific oligonucleotide method was used to detect all 104 alleles referenced on the BoLA nomenclature (http://www.projects.roslin.ac.uk/bola/drbtab.html) and to confirm the alleles detected by the PCR-RFLP method.

\section{Statistical Analysis}

Allele frequencies were calculated using the formula $f=$ number of times each allele appeared in the population/total number of alleles in the population. A logarithmic $\left(\log _{10}\right)$ transformation was applied to the antibody titer to obtain a normal distribution of data.

Gene-substitution linear mixed models were used to evaluate the effect of BoLA DRB3.2 alleles on the semicontinuous traits: antibody titers against BHV-1, BVDV, FMDV, and BLVgp51 and BLVp24 (PROC MIXED; SAS Institute, Cary, NC; Rupp et al., 2007).

Models for the immune response traits were as follows:

$$
Y_{i j}=X_{i} \beta_{i}+\Sigma_{j} \alpha_{j} B o L A_{j}+e_{i j},
$$

where $Y_{\mathrm{ij}}$ is $\log _{10}$ antibody titer; BoLA $A_{\mathrm{j}}$ is the fixed effect of the number of copies $(0,1$, or 2$)$ of $B o L A$ allele $\mathrm{j}(\mathrm{j}=$ ${ }^{*} 3,{ }^{*} 7,{ }^{*} 8,{ }^{*} 0902,{ }^{*} 10,{ }^{*} 12,{ }^{*} 16,{ }^{*} 18,{ }^{*} 22,{ }^{*} 23,{ }^{*} 24,{ }^{*} 26$, $* 27$, others (pooling the other alleles with frequencies less than $2 \%) ; \alpha_{j}$ is the vector coefficient on the number of copies of the jth BoLA allele; $\Sigma_{\mathrm{j}}$ is the summation from 1 to $\mathrm{j} ; \mathrm{X}_{\mathrm{i}}$ is the vector of environmental effects; $\beta_{\mathrm{i}}$ are the regression coefficients on the vector of fixed effects $\mathrm{X}$; and $\mathrm{e}_{\mathrm{ij}}$ is the random error term.

\section{RESULTS}

\section{BoLA DRB3.2 Genotyping}

Distribution of BoLA DRB3.2* allele frequencies found in the studied Holstein population is shown in 
Table 2. Distribution of bovine leukocyte antigen (BoLA) DRB3.2* allele frequencies in the studied population

\begin{tabular}{|c|c|c|c|}
\hline \multicolumn{2}{|c|}{ BoLA DRB3.2* allele } & \multirow[b]{2}{*}{ Alleles, n } & \multirow{2}{*}{$\begin{array}{c}\text { Allele } \\
\text { frequency }\end{array}$} \\
\hline PCR-RFLP ${ }^{1}$ & ISAG $^{2}$ & & \\
\hline 24 & 0101 or 02 & 74 & 0.1609 \\
\hline 16 & 1501 or 03 & 73 & 0.1587 \\
\hline 22 & 1101 or 02 & 53 & 0.1152 \\
\hline 11 & 0901 or 02 & 46 & 0.1000 \\
\hline 23 & $27 \mathrm{v}^{4}$ & 32 & 0.0696 \\
\hline 8 & 1201 & 31 & 0.0674 \\
\hline 3 & 1001 or 02 & 26 & 0.0565 \\
\hline 7 & 0201 & 24 & 0.0522 \\
\hline 12 & 1701 & 18 & 0.0391 \\
\hline 26 & 0601 & 16 & 0.0348 \\
\hline 18 & 1801 & 13 & 0.0283 \\
\hline 27 & $14 \mathrm{v}$ & 12 & 0.0261 \\
\hline 10 & 1601 or 02 & 10 & 0.0217 \\
\hline Others ${ }^{3}$ & & 54 & \\
\hline Total alleles & & 482 & \\
\hline Total cattle & & 241 & \\
\hline
\end{tabular}

${ }^{1}$ PCR-RFLP = nomenclature based on PCR-RFLP method.

${ }^{2} \mathrm{ISAG}=$ International Society for Animal Genetics nomenclature based on PCR-sequence-specific oligonucleotide method.

${ }^{3}$ Alleles with frequency $<2 \%$ : BoLA DRB3.2*28 (1.5\%), *29 (1.5\%), *20 (subtype *4401; 1.5\%), *32 (1.0\%),

${ }^{*} 15(0.8 \%),{ }^{*} 20$ (subtype *2901; 0.6\%), *20 (subtype *3601;0.6\%), *05 (0.4\%), *19 (0.4\%), *43 (0.4\%), *51 $(0.4 \%), * 13(0.2 \%), * 21(0.2 \%), * 02(0.2 \%), * 53(0.2 \%), * 35(0.2 \%), * 45(0.2 \%),{ }^{*} 54(0.2 \%)$.

${ }^{4} \mathrm{v}=$ variant.

Table 2. According to the restriction fragment pattern nomenclature, 29 different alleles were identified. Considering the International Society for Animal Genetics BoLA Nomenclature Committee equivalencies, 2 subtypes (*0901 and *0902) of the DRB3.2*11 allele and 3 subtypes (*2901, *3601, and *4401) of the DRB3.2*20 allele were identified.

The most frequent alleles were BoLA DRB3.2*24, *16, *11 (*0902 and *0901), and *22, with allele frequencies ranging from 10.0 to $16.09 \%$. The BoLA DRB3.2 alleles *8, *23, *3, *r, and *12 were the second most represented group, with frequencies between 3.9 and $6.9 \%$. There are 16 alleles (DRB3.2*2, *5, *13, *15, *19, each subtypes *20, *21, *28, *29, *32, *35, $* 43, * 45, * 51, * 53$, and $* 54$ ) with frequencies $<2 \%$.

\section{Association Between Antibody Titers Against Four Bovine Viruses and Polymorphism of BoLA DRB3.2* Gene}

The BoLA DRB3.2 allele substitution effect (estimated from the mixed models) on antibody titer against epitopes from structural proteins ( $e n v$ gp51 and gag p24) of BLV is presented in Table 3. Significant association was found between low antibody titer against env gp51 and BoLA DRB3.2*0902 ( $\alpha=-0.461 ; P<$ $0.0001)$ and ${ }^{* 1701}(\alpha=-0.400 ; P=0.0090)$ alleles. The BoLA DRB3.2 alleles *902 $(\alpha=-0.737 ; P<0.0001)$,
${ }^{*} 1701(\alpha=-0.607 ; P=0.0422)$, and ${ }^{* 1101}$ or 02 $(\alpha=$ $-0.372 ; P=0.0337)$ were significantly associated with low antibody titer against gag p24.

Polymorphism of the BoLA DRB3.2* gene was not significantly associated with neutralizing antibodies titer against BVDV, BHV-1, or FMDV, and consequently, alleles associated with BLV-low responders do not associate with lesser or greater antibody titer against the other 3 viruses.

\section{DISCUSSION}

Holstein cows from herds belonging to the main dairy regions of Argentina were included in the present study (Table 1). The allelic frequencies found in the study population were comparable with the international Holstein allelic frequencies communicated to date (Dietz et al., 1997b; Sharif et al., 1998; Nassiry et al., 2005; Rupp et al., 2007). Then, our results could be extrapolated to other Holstein populations.

The classification of BLV-infected cattle into 2 infection profiles (HPL and LPL) according to their proviral load and specific humoral immune response is useful in terms of the risk of transmitting the infection to BLVnegative animals.

As has been previously demonstrated, the development of HPL or LPL is associated with alleles of the BoLA DRB3.2* gene. The alleles associated with LPL 
Table 3. Bovine leukocyte antigen (BoLA) DRB3.2 allele substitution effect on antibody titers against bovine leukemia virus (BLV) gp51 and BLV p24

\begin{tabular}{lrrrr}
\hline Effect & Estimate & SE & $t$-value & $P$-value \\
\hline Anti-BLV gp51 & & & & \\
BoLA DRB3.2*1501 or 03 & 0.085 & 0.086 & 0.99 & 0.3236 \\
BoLA DRB3.2*1101 or 02 & -0.086 & 0.089 & -0.98 & 0.3298 \\
BoLA DRB3.2*0902 & -0.461 & 0.095 & -4.87 & $<0.0001$ \\
BoLA DRB3.2*1201 & 0.110 & 0.110 & 1.05 & 0.2968 \\
BoLA DRB3.2*1701 & -0.400 & 0.151 & -2.64 & 0.0090 \\
BoLA DRB3.2*0601 & 0.111 & 0.148 & 0.75 & 0.4523 \\
Anti-BLV p24 & & & & \\
BoLA DRB3.2*1501 or 03 & 0.252 & 0.169 & 1.49 & 0.1385 \\
BoLA DRB3.2*1101 or 02 & -0.372 & 0.174 & -2.14 & 0.0337 \\
BoLA DRB3.2*0902 & -0.737 & 0.186 & -3.96 & $<0.0001$ \\
BoLA DRB3.2*0201 & -0.244 & 0.245 & -1.00 & 0.3186 \\
BoLA DRB3.2*1701 & -0.607 & 0.297 & -2.04 & 0.0422 \\
BoLA DRB3.2*14 & -0.402 & 0.312 & -1.29 & 0.1980 \\
\hline
\end{tabular}

${ }^{\text {a }}$ Superscript letters show a significant effect at $P$-value $\leq 0.05$.

${ }^{1}$ Significant effect at $P$-value $\leq 0.05$. Alleles with $P>0.5$ are not shown.

${ }^{2} \mathrm{v}=$ variant

profile, specifically ${ }^{*} 0902$ and ${ }^{*} 1701$, are the markers of choice in the genetic selection of BLV-resistant cattle. On the other hand, the allele ${ }^{*} 1501$ or 03 , which has been associated with the development of HPL after infection with BLV, is a potential marker to segregate BLV-susceptible cattle (Juliarena et al., 2008). The selection of BLV-resistant and the segregation of BLV-susceptible cattle by means of the aforementioned markers represents an innovative tool as an aid to the control of BLV in heavily infected dairy farms.

As it is shown in Table 3, BoLA DRB3.2* alleles previously shown to be associated with the LPL profile $\left({ }^{*} 0902\right.$ and $\left.{ }^{*} 1701\right)$ were significantly associated with low antibody response against the main structural proteins of BLV. Additionally, the allele ${ }^{*} 1101$ or 02 , which is not associated with the LPL profile, showed significant association with low antibody response against gag p24. Neither alleles ${ }^{*} 0902$ or $*^{*} 1701$ nor allele $*_{1101}$ or 02 were significantly associated with the antibody titer against FMDV, BHV-1, or BVDV. These findings suggest that cattle selected using alleles *0902 and *1701 as BLV-resistance markers would not be more susceptible to any of the other 3 viruses mentioned.

Targeting BLV control by means of genetic selection of animals carrying alleles associated with susceptibility, such as *1501 or 03, is not desired. This allele did not show association with antibody titer against FMDV, BHV-1, or BVDV. The allele mentioned has been previously associated with high milk somatic cell score (Dietz et al., 1997b; Kelm et al., 1997). Thus, if we are to decrease the frequency of the allele to control BLV infection, the somatic cell score of the cattle population would additionally be reduced, and resistance to FMDV, BHV-1, and BVDV would not be impaired. Future studies aimed to determine higher susceptibil- ity to other infections and diseases of BoLA-selected populations would be necessary.

In the BLV system, the proviral load is associated with the antibody titer against the 2 main structural proteins. Whereas high proviral load is significantly associated with high antibody titer against both the env gp51 and the gag p24, low proviral load is strongly associated with low antibody titer against both proteins (Juliarena et al., 2007). Clearly, high antibody titer is not a perceivably efficient condition reducing proviral load from peripheral blood lymphocytes. A possible explanation for this fact is that BLV-infected lymphocytes are not a target for the specific antibodies because they are essentially silent for viral antigens. Moreover, no viral particles have been found in vivo in BLV-infected cattle (Florins et al., 2007a).

On the other hand, free viral particles are frequently found in blood of FMDV, BHV-1, and BVDV infected cattle, and this is the main dissemination strategy in the host evolved by these 3 viruses (Liess, 1990; Man and Sellers, 1990; Straub, 1990). High titers of neutralizing antibodies have been suggested to be important for the clearance of these viruses from the host (Liess, 1990; Man and Sellers, 1990; Straub, 1990). Only a minor proportion of virus-exposed naive animals become FMDV or BVDV carriers even after developing neutralizing antibodies (Liess, 1990; Man and Sellers, 1990; Gogorza et al., 2005). Almost every BHV-1 infected animal becomes a virus carrier (Straub, 1990; Kaashoek et al., 1996).

It is well-known that viral clearance from the host does not rely only on the humoral branch of the immune response; the specific cell-mediated immunity is an important defense against the viruses. Given that BLV in infected cattle with HPL has succeeded in invading 
a great number of blood lymphocytes, it is clear that the virus strategy of silencing the antigens expression efficiently evades both the humoral and cellular-specific immune responses. Conversely, LPL cattle carrying BoLA DRB3.2* alleles associated to BLV-resistance constitutes a unique model to better understand the host/virus interaction that results in the rare event of host controlling BLV infection.

In the present study, the polymorphism of the $B o L A$ $D R B^{*} 3.2^{*}$ gene was not associated with antibody titers against FMDV, BHV-1, or BVDV. The association found between BoLA DRB3.2*0902 and *1701 and antibody titer against BLV structural proteins is an obvious effect of the association between these antibody titers and the proviral load in BLV-infected cattle previously reported (Juliarena et al., 2007). The association found in the BLV system between allele *1101 or 03 and low antibody titer against gag p24 is not related to BLV-resistance. Further studies involving other parameters such as the persistence or viral load status concerning FMDV, BHV-1, or BVDV and BoLA DRB3.2* polymorphism are needed. These parameters would probably represent a better indicator of resistance against the aforementioned viruses.

\section{ACKNOWLEDGMENTS}

The authors thank José La Torre, Blanca Robiolo, and technical team from Centro de Virología Animal, Buenos Aires, Argentina, for their helpful contribution to titrate neutralizing antibodies against FMDV and enriching discussions. The authors also thank Patricia Bani and Norma Rodriguez for technical assistance and María Nieves Esteban for English language and grammar proofreading. This work was partially supported by grants to Esteban and Ceriani from FONCYT (Fondo para la Investigación Científica y Tecnológica; 0804818/1998 and 08-11083/2002), and to Núcleo Consolidado SAMP from CIC and SeCyT-UNCPBA.

\section{REFERENCES}

Babiuk, L. A., S. van Drunen Littel-van den Hurk, and S. K. Tikoo. 1996. Immunology of bovine herpesvirus 1 infection. Vet. Microbiol. 53:31-42.

Bolin, S. R. 1995. Control of bovine viral diarrhea infection by use of vaccination. Vet. Clin. North Am. Food Anim. Pract. 11(Suppl. 3):615-625.

Bolin, S. R., and J. F. Ridpath. 1995. Assessment of protection from systemic infection or disease afforded by low to intermediate titers of passively acquired neutralizing antibody against bovine viral diarrhea virus in calves. Am. J. Vet. Res. 56(Suppl. 6):755-759.

Capozzo, A. V., O. H. Periolo, B. Robiolo, C. Seki, J. L. La Torre, and P. R. Grigera. 1997. Total and isotype humoral responses in cattle vaccinated with foot and mouth disease virus (FMDV) immunogen produced either in bovine tongue tissue or in BHK-21 cell suspension cultures. Vaccine 15(Suppl. 6-7):624-630.
Dietz, A. B., N. D. Cohen, L. Timms, and M. E. Jr. Kehrli. 1997b Bovine Lymphocyte Antigen class II alleles as risk factors for high somatic cell counts in milk of lactating dairy cows. J. Dairy Sci. 80:406-412.

Fauquet, C. M., M. A. Mayo, J. Maniloff, U. Desselberger, and L. A. Ball. 2005. Virus Taxonomy, VIIIth Report of the ICTV. Elsevier Academic Press, London, UK.

Florins, A., N. Gillet, B. Asquith, M. Boxus, C. Burteau, J. C. Twizere, P. Urbain, F. Vandermeers, C. Debacq, M. T. Sanchez-Alcaraz, I. Schwartz-Cornil, P. Kerkhofs, G. Jean, A. Théwis, J. Hay, F. Mortreux, E. Wattel, M. Reichert, A. Burny, R. Kettmann, C. Bangham, and L. Willems. 2007a. Cell dynamics and immune response to BLV infection: A unifying model. Front. Biosci. 12:1520-1531.

Florins, A., N. Gillet, M. Boxus, P. Kerkhofs, R. Kettmann, and L. Willems. 2007b. Even attenuated bovine leukemia virus proviruses can be pathogenic in sheep. J. Virol. 81(Suppl. 18):1019510200.

Garcia-Briones, M. M., G. C. Russell, R. A. Oliver, C. Tami, O. Taboga, E. Carrillo, E. L. Palma, F. Sobrino, and E. J. Glass. 2000. Association of bovine DRB3 alleles with immune response to FMDV peptides and protection against viral challenge. Vaccine 19(Suppl. 9-10):1167-1171.

Gillet, N., A. Florins, M. Boxus, C. Burteau, A. Nigro, F. Vandermeers, H. Balon, A. B. Bouzar, J. Defoiche, A. Burny, M. Reichert, R. Kettmann, and L. Willems. 2007. Mechanisms of leukemogenesis induced by bovine leukemia virus: Prospects for novel antiretroviral therapies in human. Retrovirology 16:4-18.

Gogorza, L. M., P. E. Moran, J. L. Larghi, R. Seguí, C. Lissarrague, M. Saracco, M. Braun, and E. N. Esteban. 2005. Detection of bovine viral diarrhea virus (BVDV) in seropositive cattle. Prev. Vet. Med. 72(Suppl. 1-2):49-54.

Gutierrez, S. E., G. L. Dolcini, G. H. Arroyo, C. Rodríguez Dubra, J. F. Ferrer, and E. N. Esteban. 2001. Development and evaluation of a highly sensitive and specific blocking enzyme-linked immunosorbent assay and polymerase chain reaction assay for diagnosis of bovine leukemia virus infection in cattle. Am. J. Vet. Res. 62:1571-1577.

Juliarena, M. A., S. E. Gutierrez, and C. Ceriani. 2007. Determination of proviral load in bovine leukemia virus-infected cattle with and without lymphocytosis. Am. J. Vet. Res. 68(Suppl. 11):12201225.

Juliarena, M. A., M. Poli, L. Sala, C. Ceriani, S. Gutierrez, G. Dolcini, B. Mariño, C. Rodríguez-Dubra, and E. N. Esteban. 2008. Association of BLV-infection profiles with alleles of BoLA DRB3.2 gene. Anim. Genet. 39:432-438.

Kaashoek, M. J., F. A. M. Rijsewijk, and J. T. Van Oirschot. 1996. Persistence of antibodies against bovine herpesvirus 1 and virus reactivation two to three years after infection. Vet. Microbiol. 53:103-110.

Kelling, C. L. 2004. Evolution of bovine viral diarrhea virus vaccines. Vet. Clin. North Am. Food Anim. Pract. 20(Suppl. 1):115-129.

Kelm, S. C., J. C. Detilleux, A. E. Freeman, M. E. Kehrli Jr., A. B. Dietz, L. K. Fox, J. E. Butler, and D. H. Kelley. 1997. Genetic association between parameters of innate immunity and measures of mastitis in periparturient Holstein cattle. J. Dairy Sci. 80:17671775 .

Liess, B. 1990. Bovine Viral Diarrhea Virus. Pages 247-266 in Virus Infections of Ruminants. Z. Dinter and B. Morein, ed. Elsevier Science Publishers BV, New York, NY.

Maisonnave, J., and C. R. Rossi. 1982. A microtiter test for detecting and titrating non-cytopathogenic bovine viral diarrhea virus. Arch. Virol. 72:279-287.

Man, J. A., and R. F. Sellers. 1990. Foot-and-Mouth Disease Virus. Pages 503-511 in Virus Infections of Ruminants. Z. Dinter and B. Morein, ed. Elsevier Science Publishers BV, New York, NY.

Nassiry, M. R., F. Eftekhar Shahroodi, J. Mosafer, A. Mohammadi, E. Manshad, S. Ghazanfari, M. R. Mohammad Abadi, and G. E. Sulimova. 2005. Analysis and frequency of bovine lymphocyte antigen (BoLA DRB3) alleles in Iranian Holstein cattle. Russ. J. Genet. $41: 664-668$. 
Orsel, K., M. C. de Jong, A. Bouma, J. A. Stegeman, and A. Dekker. 2007. The effect of vaccination on foot and mouth disease virus transmission among dairy cows. Vaccine 25(Suppl. 2):327-335.

Reed, L. J., and H. A. Muench. 1938. A simple method of estimating fifty percent endpoints. Am. J. Hyg. 27:493-497.

Reichert, M., G. H. Cantor, L. Willems, and R. Kettmann. 2000. Protective effects of a live attenuated bovine leukaemia virus vaccine with deletion in the R3 and G4 genes. J. Gen. Virol. 81(Suppl. 4):965-969.

Robiolo, B., C. Seki, N. Fondevilla, P. Grigera, E. Scodeller, O. Periolo, J. La Torre, and N. Mattion. 2006. Analysis of the immune response to FMDV structural and non-structural proteins in cattle in Argentina by the combined use of liquid phase and 3ABC-ELISA tests. Vaccine 24(Suppl. 7):997-1008.

Rupp, R., A. Hernandez, and B. A. Mallard. 2007. Association of bovine leukocyte antigen (BoLA) DRB3.2 with immune response, mastitis and production and type traits in Canadian Holsteins. J. Dairy Sci. 90:1029-1038.
Sharif, S., B. A. Mallard, B. N. Wilkie, J. M. Sargeant, H. M. Scott, J. C. M. Dekkers, and K. E. Leslie. 1998. Associations of the bovine major histocompatibility complex DRB3 (BoLA DRB3) alleles with occurrence of diasease and milk somatic cell score in Canadian dairy cattle. Anim. Genet. 29:185-193.

Straub, O. C. 1990. Infectious bovine rhinotracheitis virus. Pages $71-$ 99 in Virus Infections of Ruminants. Z. Dinter and B. Morein, ed. Elsevier Science Publishers BV, New York, NY.

Van der Maaten, M. J. J. M. Miller, and C. A. Whetstone. 1985. Ovarian lesions induced in heifers by inoculation with modified-live infections bovine rhinotracheitis virus on the day after breeding. Am. J. Vet. Res. 46:1996-1999.

van Oirschot, J. T. 1999. Diva vaccines that reduce virus transmisión J. Biotechnol. 73(Suppl. 2-3):195-205.

Willems, L., P. Kerkhofs, F. Dequiedt, D. Portetelle, M. Mammerickx, A. Burny, and R. Kettmann. 1994. Attenuation of bovine leukemia virus by deletion of R3 and G4 open reading frames. Proc. Natl. Acad. Sci. USA 91(Suppl. 24):11532-11536. 